Bull. Chem. Soc. Ethiop. 2016, 30(1), 153-160.

Printed in Ethiopia

ISSN 1011-3924

DOI: http://dx.doi.org/10.4314/bcse.v30i1.15

(C) 2016 Chemical Society of Ethiopia

\title{
ELECTROCHEMICAL SYNTHESIS AND CHARACTERIZATION OF BILAYERS OF POLY(O-AMINOPHENOL)/POLYPYRROLE/LIGNIN COMPOSITES FOR ENHANCED CHARGE STORAGE IN SUPERCAPACITORS
}

\author{
Shimelis Admassie* \\ Department of Chemistry, Addis Ababa University, P. O. Box 1176, Addis Ababa, Ethiopia
}

(Received August 17, 2015; revised November 4, 2015)

\begin{abstract}
Using simple electrosynthesis methods a single and bilayer of conducting polymers, polypyrrole and poly(o-aminophenol) with biopolymer lignin hybrid composites were formed on gold electrodes. The specific capacitance of the single polymer-lignin composite value of $400 \mathrm{~F} / \mathrm{g}$ obtained from galvanostatic charge-discharge experiment at $1 \mathrm{~A} / \mathrm{g}$ is improved to a value of $514 \mathrm{~F} / \mathrm{g}$ in the bilayer polymer-lignin composite systems. The charge capacity is also improved from $61 \mathrm{mAh} / \mathrm{g}$ to $121 \mathrm{mAh} / \mathrm{g}$ by forming a bilayer of conducting polymers. Moreover, the charge retention during self-discharge is improved in the bilayer system.
\end{abstract}

KEY WORDS: Supercapacitors, Conducting polymers, Lignin

\section{INTRODUCTION}

There is a growing interest in finding cheap, scalable and efficient energy storage materials for use in electrochemical technologies like supercapacitors (SCs), batteries and fuel cells since renewable energy conversion technologies like solar and wind are intermittent [1-3]. Recently, SCs are attracting great attention due to the increasing demand of a new kind of electrical power source having high specific power and long durability [4]. SCs can be classified into two groups, as electrical double layer capacitors (EDLCs) and pseudo-capacitors or redox capacitors. EDLCs store energy through the accumulation of charges at the electrode-electrolyte interface, while redox capacitors store energy as a result of very fast faradaic redox reactions involving the passage of charge across the double layer during charging and discharging [1]. High surface area carbons and nanostructured conducting materials like $\mathrm{TiO}_{2}$ nanotubes are some examples of materials used for EDLC. Transition metal oxides such as $\mathrm{RuO}_{2}, \mathrm{Fe}_{3} \mathrm{O}_{4}$ and $\mathrm{MnO}_{2}$, as well as conductive polymers such as polypyrrole, polyaniline and polythiophene are examples of materials used in redox capacitor electrodes.

Several studies proved that making a hybrid material of conjugated polymers with transition metal oxides [5-8], carbon nanomaterials [5-8], polyoxometalates [9-12], and quinone containing biomaterials [12-16] significantly improve the energy storage capacity of SCs by combing the redox capacitance and EDLC from the different components.

In this work we incorporated the biopolymer lignin in $o$-aminophenol $(o-\mathrm{APh})$ by electrosynthesis of bilayers of $\mathrm{p}(o-\mathrm{APh})$ and $\mathrm{pPy}$ for a possible improvement of the charge storage capacity of the polypyrrole/lignin systems. Since the $\mathrm{p}(o-\mathrm{APh})$ and $\mathrm{pPy} / \mathrm{LG}$ systems do have redox activities at different potentials, the potential window for charge storage can be widened and could possibly improve the energy and power density of charge storage devices that can be developed by incorporating such conducting polymers and biopolymer composites.

\section{EXPERIMENTAL}

Pyrrole (Py) was distilled prior to use, $o$-aminophenol (o-APh), and perchloric acid (SigmaAldrich) were used as received without further purification. The lignosulfonate (LG) was from Medwestveco ( $\mathrm{LC} 30, \mathrm{Mw}=13,400)$. Cyclic voltammetry and galvanostatic experiments were

*Corresponding author. E-mail: shimelis.admassie@aau.edu.et; shimadm09@gmail.com 
carried out using an Autolab PGStat 10 (EchoChemie, The Netherlands). Gold electrodes (Au; $\mathrm{CH}$ Instruments; $0.0314 \mathrm{~cm}^{2}$ ) were polished with $0.05 \mu \mathrm{m}$ alumina and rinsed well with water before use. A platinum wire and a $\mathrm{Ag} / \mathrm{AgCl} / \mathrm{KCl}(3.0 \mathrm{M})$ were used as counter and reference electrodes, respectively. All voltammograms were recorded in ambient atmosphere. The electrochemical quartz crystal microbalance studies were investigated using a Q-Sense E4 instrument, AB, Sweden and gold-deposited quartz crystals. Any material adsorbed or deposited on the crystal surface induces an increase in the resonant frequency, $\left(\Delta f=f-f_{o}\right)$, where $f_{o}$ is the its fundamental resonance frequency. For a rigid and thin film, $\Delta \mathrm{f}$ is directly related to the depostited mass per unit area $\left(\mathrm{mg} / \mathrm{m}^{2}\right), \Delta \mathrm{m}$, by the Sauerbrey equation:

$\Delta \mathrm{m}=-\mathrm{C}(\Delta \mathrm{f} / \mathrm{n})$

where $\mathrm{C}\left(=1.77 \mathrm{ng} / \mathrm{cm}^{2}\right.$ at fo $\left.5 \mathrm{MHz}\right)$ is the constant for the mass sensitivity, and $\mathrm{n}$ is the overtone number. Q-Soft was used to directly convert the $\Delta \mathrm{f}$ to $\Delta \mathrm{m}$. The electrosynthesis of $\mathrm{p}(o-$ $\mathrm{APh}$ ) was carried out potentiodynamically on gold electrode from $50 \mathrm{mM}$ of $o-\mathrm{APh}$ in $0.5 \mathrm{M}$ $\mathrm{H}_{2} \mathrm{SO}_{4}$ by cycling the potential between -0.2 to $0.90 \mathrm{~V}$ for 95 cycles at a scan rate of $50 \mathrm{mV} / \mathrm{s}$. $\mathrm{pPy} / \mathrm{LG}$ was galvanostatically deposited on bare gold electrode and on top of $\mathrm{p}(o-\mathrm{APh})$ from a solution consisting of $0.025 \mathrm{M}$ Py and $5.0 \mathrm{mg} / \mathrm{mL}$ of $\mathrm{LG}$ in $0.1 \mathrm{M} \mathrm{HClO}_{4}$.

\section{RESULTS AND DISCUSSIONS}

The potentiodynamic polymerization of $o-\mathrm{APh}$ on a gold electrode is depicted in Figure 1(A). The irreversible peak at around $0.8 \mathrm{~V}$ in the first cycle (Figure 1(A)) corresponds to the oxidation of the monomer $o$-APh. With increasing cycle number, the anodic peak corresponding to the oxidation of the monomer decreases since the electrode surface begins to be covered by the $\mathrm{p}(o-\mathrm{APh})$ particles. Moreover, a new reversible redox peak corresponding to the redox reaction of the $\mathrm{p}(o-\mathrm{APh})$ film around $0.1 \mathrm{~V}$ develops and grows with increasing cycle number (Figure 1(A)). Similar CV growth curves are also reported by several authors for $\mathrm{p}(o-\mathrm{APh})$ and for related polyaniline derivatives [17-19]. Typical $\mathrm{CV}$ of $\mathrm{p}(o-\mathrm{APh})$ in monomer-free $0.1 \mathrm{M}$ $\mathrm{HClO}_{4}$ acid is depicted in Figure 1(B) showing the characteristic redox peaks of $\mathrm{p}(o-\mathrm{APh})$.

Chronopotentiometric curves recorded during galvanostatic electropolymerization of $\mathrm{pPy} / \mathrm{LG}$ on the gold electrode and $\mathrm{pPy} / \mathrm{LG}$ on $\mathrm{p}(o-\mathrm{APh})$-modified gold electrode for a charge of $75 \mathrm{mC} / \mathrm{cm}^{2}$ are shown in Figure 2. As evident in Figure 2, the electropolymerization of $\mathrm{pPy} / \mathrm{LG}$ at $\mathrm{p}(o-\mathrm{APh})$-modified gold electrode occurs at slightly higher potential than that of the polymerization of $\mathrm{pPy} / \mathrm{LG}$ at gold electrode, particularly during the first $100 \mathrm{~s}$ of the electropolymerization. This could be due to the slightly lower of mass of $\mathrm{pPy} / \mathrm{LG}$ being deposited at $\mathrm{p}(o-\mathrm{APh})$-modified gold electrode than at bare gold electrode for similar charge of $75 \mathrm{mC} / \mathrm{cm}^{2}$.

The mass changes estimated from EQCM measurements for the $\mathrm{p}(o-\mathrm{APh}), \mathrm{pPy} / \mathrm{LG}$ and $\mathrm{p}(o-$ $\mathrm{APh} / \mathrm{pPy} / \mathrm{LG}$ are shown in Figure 3. The mass of $\mathrm{pPy} / \mathrm{LG}$ deposited on gold electrode was estimated to be $50.6 \mu \mathrm{g}$ while that of $\mathrm{pPy} / \mathrm{LG}$ deposited on $\mathrm{p}(o-\mathrm{APh})$ modified gold electrode was $46.5 \mu \mathrm{g}$ for a deposition charge of $75 \mathrm{mC} / \mathrm{cm}^{2}$. The mass of $\mathrm{p}(o-\mathrm{APh})$ deposited in gold electrode until a positive charge of $5.26 \mathrm{mC} / \mathrm{cm}^{2}$ reached was $11.0 \mu \mathrm{g}$. This gives a total mass of $57.5 \mu \mathrm{g}$ for the bilayer conducting polymers and lignin composites. 

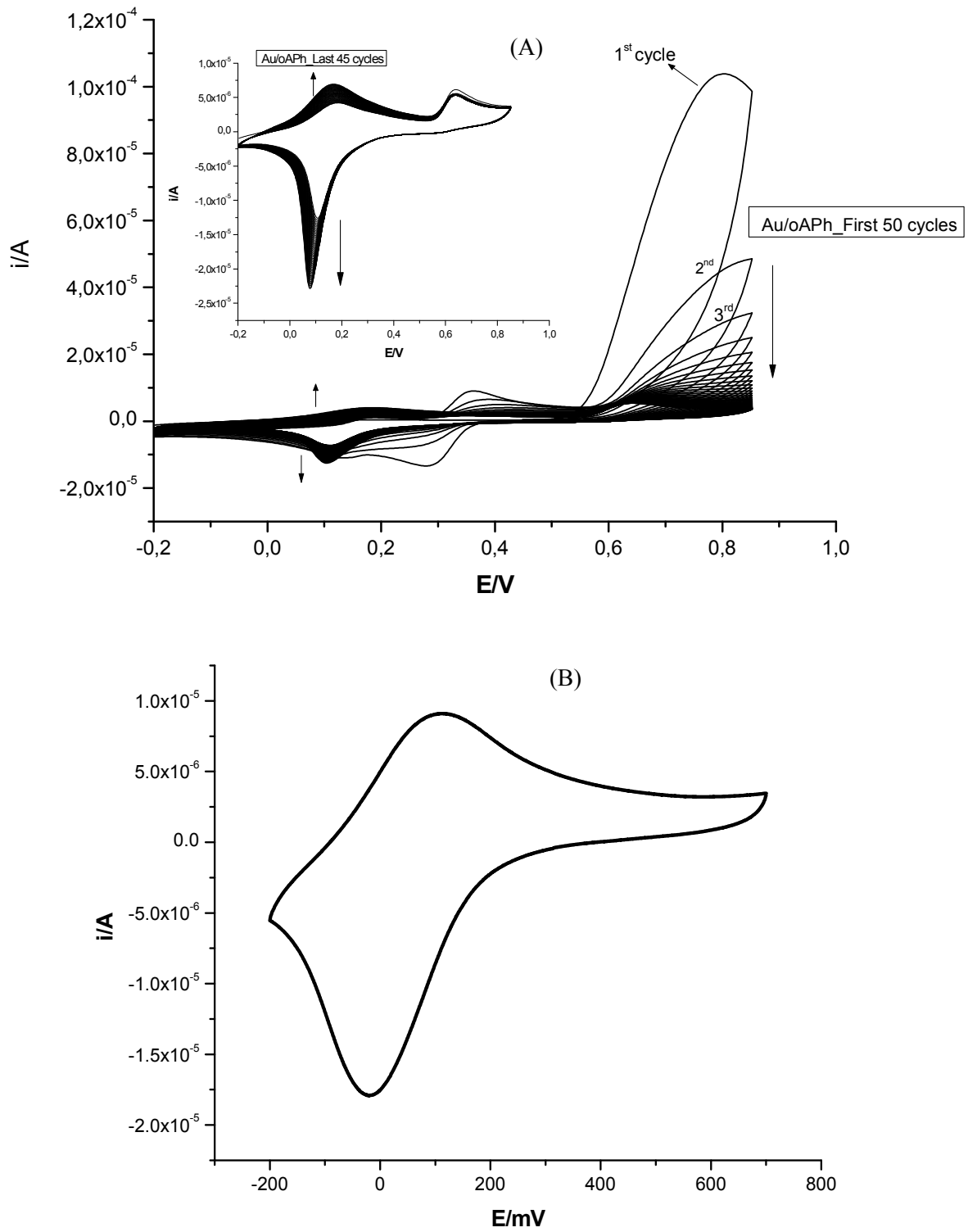

Figure 1. (A) Potentiodynamic electrosynthesis of $\mathrm{p}(o-\mathrm{APh})$ at gold electrode from $50 \mathrm{mM}$ of $o$ $\mathrm{APh}$ in $0.5 \mathrm{M} \mathrm{H}_{2} \mathrm{SO}_{4}$ for the first 50 cycles and inset for the last 45 cycles at a scan rate of $50 \mathrm{mV} / \mathrm{s}$. (B) Cyclic voltammograms of $\mathrm{p}(\mathrm{o}-\mathrm{APh})$ in monomer free $0.1 \mathrm{M}$ $\mathrm{HClO}_{4}$ acid solution at a scan rate of $100 \mathrm{mV} / \mathrm{s}$. 


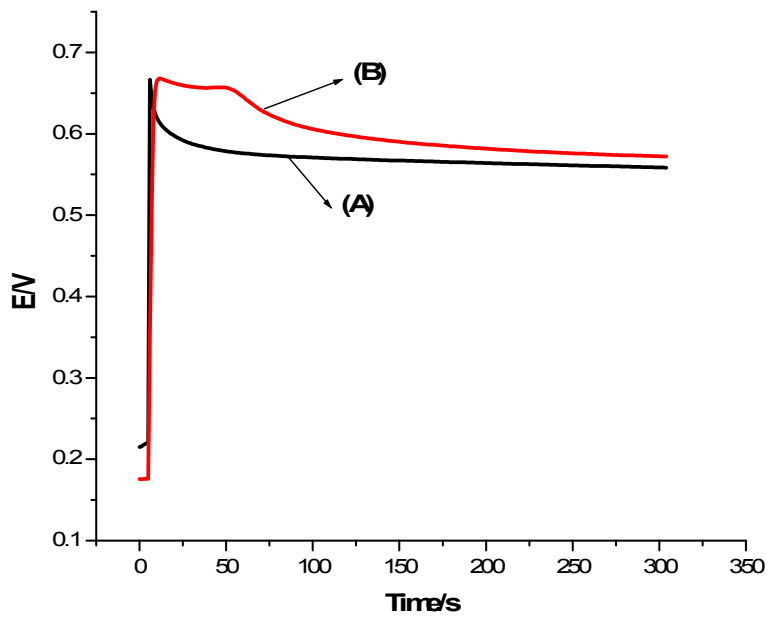

Figure 2. Chronopotentiometric curves recorded during galvanostatic electropolymerization of (A) $\mathrm{pPy} / \mathrm{LG}$ on gold electrode and (B) $\mathrm{pPy} / \mathrm{LG}$ on a $\mathrm{p}(o-\mathrm{APh})$-modified gold electrode.

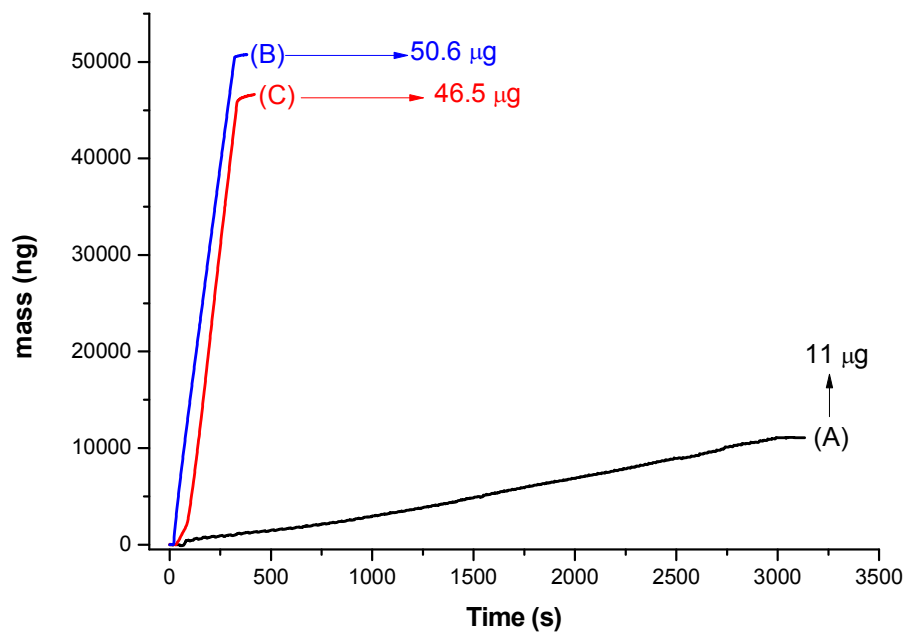

Figure 3. Mass changes obtained for the deposition of (A) $\mathrm{p}(o-\mathrm{APh})$ on gold, (B) $\mathrm{pPy} / \mathrm{LG}$ on gold and $(\mathrm{C}) \mathrm{pPy} / \mathrm{LG}$ on $\mathrm{p}(o-\mathrm{APh})$ modified gold electrodes.

Typical cyclic voltammograms of the composites obtained at different scan rates are depicted in Figure 4A. Two distinct reversible redox peaks were observed. The redox peak at more anodic potentials (II/III) were due to the redox activity of the quinone functional groups while the remaining peaks (I/IV) were due to the redox activity of $\mathrm{p}(o-\mathrm{APh})$. The peak current for each redox peak was found to vary linearly with scan rate (Figure 4B) suggesting surface confined redox process taking place in the composite system. 
The specific capacitances for the bilayer and single layer conducting polymer composites with lignin are compared in Figure 5. The specific capacitances at each potential were calculated from the cyclic voltammograms using Equation 2 and depicted in Figure 5:

$C=i / v$

where $\mathrm{C}$ is the specific capacitance in farads per grams $(\mathrm{F} / \mathrm{g}), i$ is current response in the cyclic voltammograms divided by the mass of the active materials determined from the EQCM $(\mathrm{A} / \mathrm{g})$ and $v$ is the scan rate $(\mathrm{V} / \mathrm{s})$.
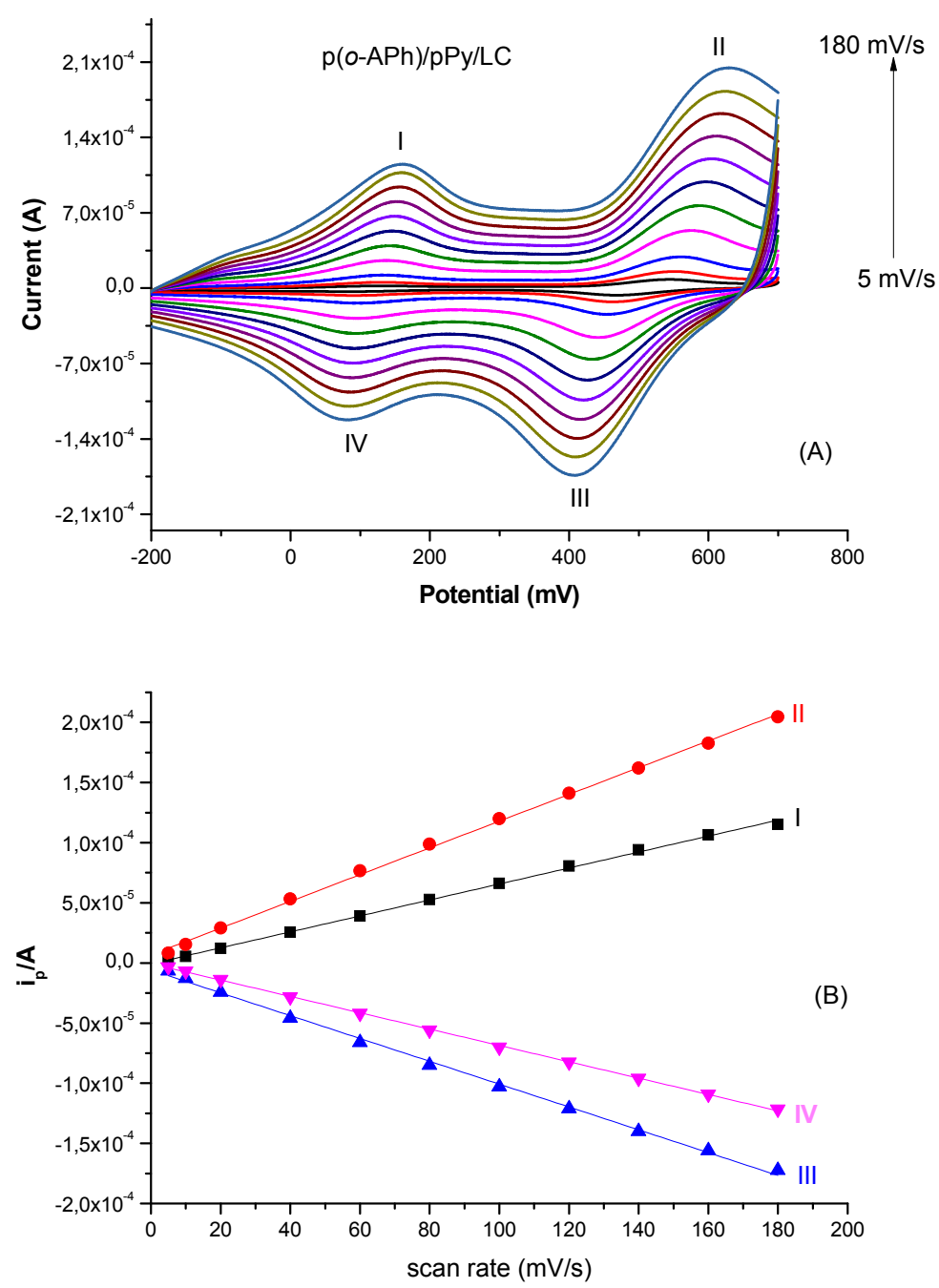

Figure 4. (A) Cyclic voltammograms of $\mathrm{p}(o-\mathrm{APh}) / \mathrm{pPy} / \mathrm{LG}$ in monomer free $0.1 \mathrm{M} \mathrm{HClO}_{4}$ acid solution at different scan rates. (B) Plots of peak currents versus scan rates. 


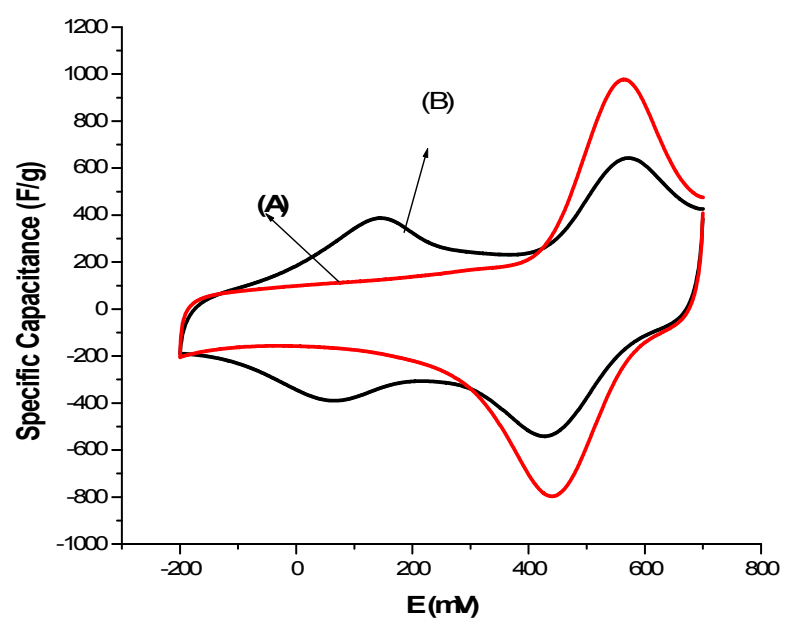

Figure 5. Comparison of the specific capacitances of (A) pPy/LG and (B) $\mathrm{p}(o-\mathrm{APh}) / \mathrm{pPy} / \mathrm{LG}$ in $0.1 \mathrm{M} \mathrm{HClO}_{4}$ at a scan rate of $100 \mathrm{mV} / \mathrm{s}$.
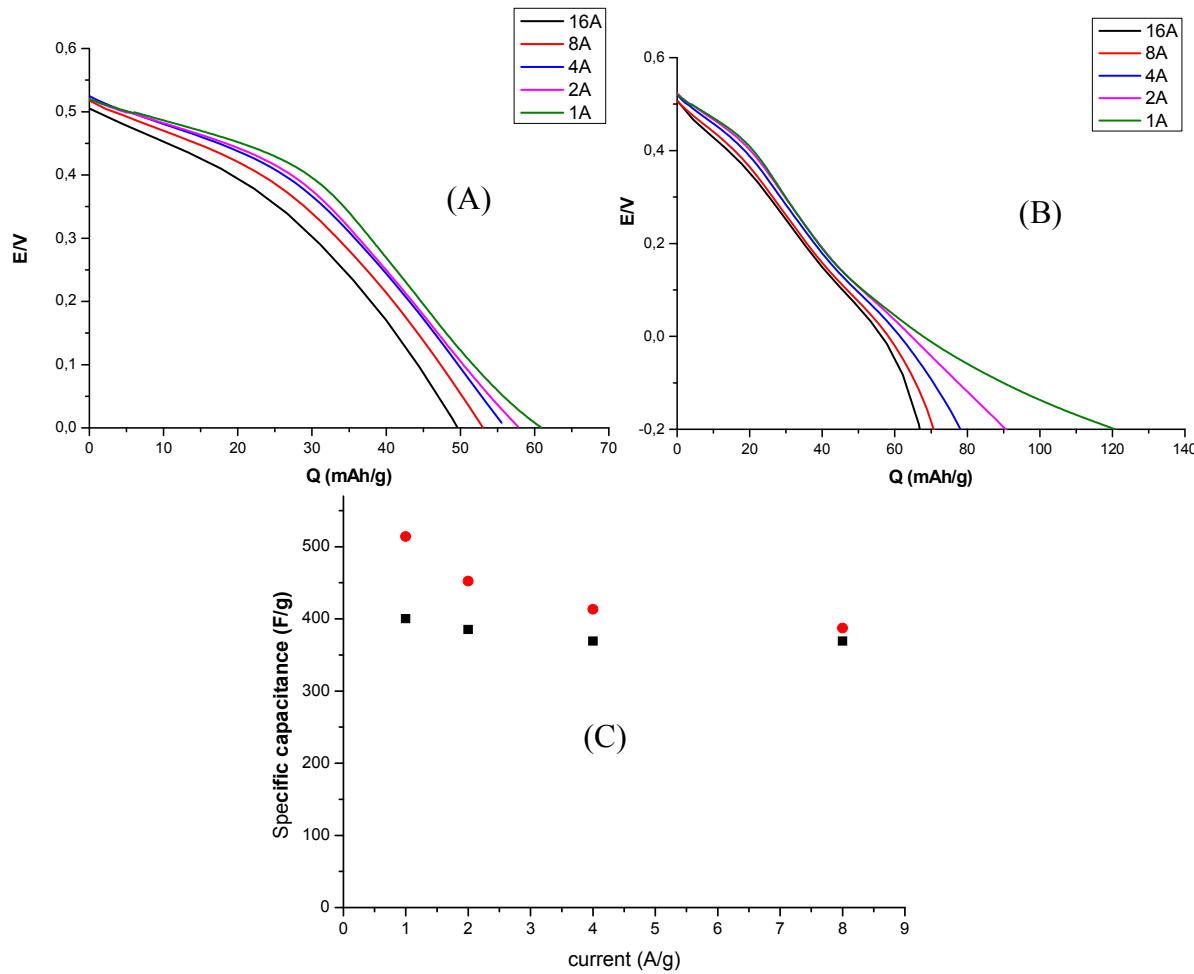

Figure 6. Discharge curves for (A) $\mathrm{pPy} / \mathrm{LG},(\mathrm{B}) \mathrm{p}(o-\mathrm{APh}) / \mathrm{pPy} / \mathrm{LG}$ at different currents, (C) specific capacitance values of $(\boldsymbol{\bullet}) \mathrm{pPy} / \mathrm{LG}$ and $(\bullet) \mathrm{p}(o-\mathrm{APh}) / \mathrm{pPy} / \mathrm{LG}$ at different currents.

Bull. Chem. Soc. Ethiop. 2016, 30(1) 
The single layer $\mathrm{pPy} / \mathrm{LG}$ and the bilayer $\mathrm{p}(o-\mathrm{APh}) / \mathrm{pPy} / \mathrm{LG}$ composites gave a peak capacitance of $885 \mathrm{~F} / \mathrm{g}$ and $590 \mathrm{~F} / \mathrm{g}$, respectively, at the redox potentials of the LG. The lower peak capacitance obtained for the bilayer composite is due to the lesser amount of LG deposited in the composites. However, an additional peak capacitance of $388 \mathrm{~F} / \mathrm{g}$ was found in the redox potential of the conducting polymer, $\mathrm{p}(o-\mathrm{APh})$. Hence, the potential window in the bilayer conducting polymer-lignin composite system that goes down to $-0.2 \mathrm{~V}$ which widens the potential window and increase the energy density of supercapacitors based on such bilayer systems. This effect is more clearly seen from the values of the charge capacity values estimated from the glavanostatic charge-discharge experiments.

The discharge properties of each system at different current densities are depicted in Figure 6 ((A) and (B)). It can be seen that the specific charge of the pPy/LG system is $61 \mathrm{mAh} / \mathrm{g}$ (Figure 6 (A)) while that of the bilayer system is $121 \mathrm{mAh} / \mathrm{g}$ (Figure 6 (B)) at $1 \mathrm{~A} / \mathrm{g}$. Hence, by forming bilayers of conducting polymers, the charge storage capacity of the $\mathrm{pPy} / \mathrm{LG}$ conducting polymer/biopolymer composite was significantly improved.

The specific capacitance values obtained from the discharge curves were plotted as a function of current density in Figure 6 (C). The specific capacitance values for the bilayer conducting polymer-lignin composite system were found to be higher than the single conducting polymer-lignin composite system where the differences were more pronounced at lower currents.

Self-discharge is known to be one of the problems in supercapacitors [20-22]. Typical discharge curves for $\mathrm{p}(o-\mathrm{APh}) / \mathrm{pPy} / \mathrm{LG}$ composites obtained after charging up to $0.6 \mathrm{~V}$ at $1 \mathrm{~A} / \mathrm{g}$ and waiting for different times at open circuit potential are depicted in Figure 7.

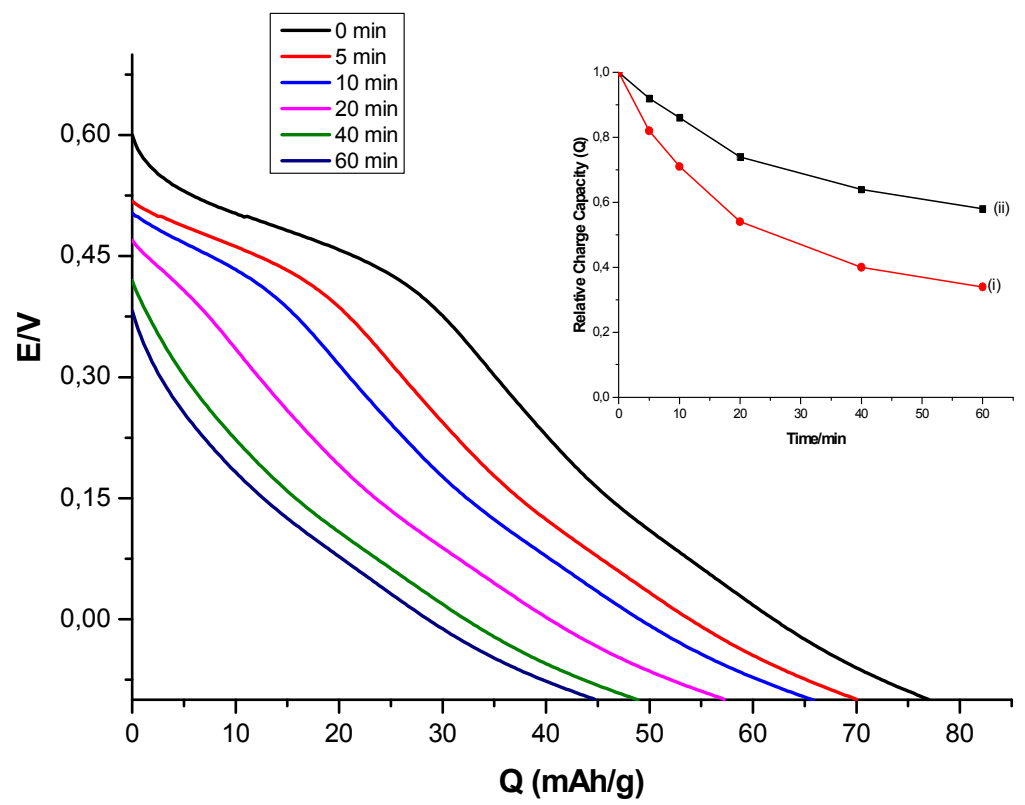

Figure 7. Self-discharge curves at different waiting times for $\mathrm{p}(o-\mathrm{APh}) / \mathrm{pPy} / \mathrm{LG}$ composites and insert relative charge capacity for (i) $\mathrm{pPy} / \mathrm{LG}$, (ii) $\mathrm{p}(o-\mathrm{APh}) / \mathrm{PPy} / \mathrm{LG}$ composites.

The self-discharge trend in both the single and bilayer system is similar. However, the bilayer-lignin composite system retains more charge at any chosen time than the single layer lignin composite systems and hence such an approach, using bilayer or even multilayer 
composite systems, might alleviate self-discharge problems in use of conducting polymer based electrodes.

\section{CONCLUSIONS}

By electropolymerizing $\mathrm{pPy} / \mathrm{LG}$ on top of $\mathrm{p}(o-\mathrm{APh})$ it was possible to extend the potential window for charge storage, leading to higher energy and power densities. These high capacitance in a wider potential window and a lessened self-discharge in aqueous solution may be useful in supercapacitor devices.

\section{ACKNOWLEDGEMENTS}

Financial support by the Knut and Alice Wallenberg Foundation through Prof. Olle Inganäs and the International Science Program (ISP), Sweden, is greatly acknowledged.

\section{REFERENCES}

1. Inganäs, O.; Admassie, S. Adv. Mater. 2014, 26, 830.

2. Wondimu, B.; Admassie, S. Bull. Chem. Soc. Ethiop. 2012, 26, 449.

3. Wondimu, B.; Admassie, S. J. Power Sources 2012, 216, 502.

4. Graeme, A.S.; Pon, K.; Adam, S.B. J. Power Sources 2011, 196. 1.

5. Wang, G.; Zhang, L.; Zhang, J. Chem. Soc. Rev. 2012, 41, 797.

6. Bose, S.; Kuila, T.; Mishra, A.K.; Rajasekar, R.; Kim, N.H.; Lee, J.H. J. Mater. Chem. 2012 , 22, 767.

7. Yu, G.; Xie, X.; Pan, L.; Bao, Z.; Cui, Y. Nano Energy 2013 2, 213.

8. Xiong, P.; Zhu, J.; Wang, X. J. Power Sources 2015, 294, 31.

9. Herrmann, S.; Ritchie, C.; Streb, C. Dalton Trans. 2015, 44, 7092.

10. Cui, Z; Guo, C.X.; Yuan, W.; Li, C.M. Phys. Chem. Chem. Phys. 2012, 14, 12823.

11. White, A.M.; Slade, R.C.T. Electrochim. Acta 2004, 49, 861.

12. Admassie, S.; Elfwing, A.; Jager, E.W.H.; Bao, Q.; Inganäs, O. J. Mater. Chem. A 2014, 2 , 1974.

13. Kim, S.-K.; Kim, Y.K.; Lee, H.; Lee, S.B.; Park, H.S. ChemSusChem 2014, 7, 1094.

14. Milczarek, G.; Inganäs, O. Science 2012, 335, 1468.

15. Admassie, S.; Nilsson, T.Y.; Inganäs, O.; Phys. Chem. Chem. Phys. 2014, 16, 24681.

16. Leguizamon, S.; Diaz-Orellana, K.P.; Velz, J.; Thies, M.C.; Roberts, M.E. J. Mater. Chem. A 2015, 3, 11330 .

17. Jaidev; Ramaprabhu, S. J. Mater. Chem. 2012, 22, 18775.

18. Yadegari, H.; Heli, H.; Jabbari, A. J. Solid State Electrochem. 2013, 17, 2203.

19. Heli, H.; Yadegari, H.; Jabbari, A. Mater. Chem. Phys. 2012, 134, 21.

20. Andreas, H.A. J. Electrochem. Soc. 2015, 162, A5047.

21. Olsson, H.; Stromme, M.; Nyholm, L.; Sjodin, M. J. Phys. Chem. C 2014, 118, 29643.

22. Olsson, H.; Qiu, Z.; Stromme, M.; Nyholm, L.; Sjodin, M. Phys. Chem. Chem. Phys. 2015, $17,11014$. 